\title{
Olhares para a História: pós-colonialismo, estudos subalternos e decolonialidade
}

\author{
Miradas para la Historia: poscolonialismo, estudios subalternos y \\ decolonialidad
}

Looks at History: post-colonialism, subaltern studies and decoloniality

Daniele Brocardo ${ }^{1}$

Caroline Tecchio ${ }^{2}$

\begin{abstract}
Resumo
A ideia deste trabalho surge a partir da realização de uma disciplina no curso de doutorado em História. Nesta disciplina nos propusemos discutir os textos teóricos desenvolvidos por autoras e autores que são identificados com os movimentos teóricos conhecidos como pós-colonialismo, estudos subalternos e decolonialidade. A partir destas leituras e de uma atividade desta disciplina (ler uma tese desenvolvida no campo da História), percebemos a ausência de trabalhos neste campo de conhecimento. Assim, nasce o questionamento que estrutura este trabalho: Como estes estudos podem contribuir para a escrita da História? Os historiadores estão em constante processo de repensar a forma que a história é escrita e ensinada, porém ela ainda continua centrada na Europa, em homens brancos e ocidentais. Assim, por mais que se tenha avançado nas críticas a esta perspectiva, acreditamos que os estudos decolonias, podem contribuir muito para o campo das ciências Humanas. Para tanto escolhemos para a análise os textos devolvidos pelos seguintes autores: Edward W. Said, Gayatri C. Spivak, Walter D. Mignolo e Boaventura de Sousa Santos. Espera-se com esta análise perceber algumas das contribuições que estes autores podem trazer para o conhecimento histórico.
\end{abstract}

Palavras-Chave: Aporte teórico; Ciências Humanas; Descolonização epistêmica.

\section{Resumen}

La ideia de este trabajo surgió a partir de la realización de una disciplina en el curso de doctorado en Historia. En esta disciplina nos hemos propuesto discutir los textos teóricos desarrollados por autoras y autores que son identificados con los movimientos teóricos conocidos como poscolonialismo, estudios subalternos y decolonialidad. A partir de estas lecturas y de una actividad desarrollada en la disciplina (leer una tesis desarrollada en el campo de la Historia), nos dimos cuenta de la ausencia de trabajos en este campo de conocimiento. De este modo, nace el cuestionamiento que estructura este trabajo: Como estos estudios pueden contribuir para la escrita de la Historia? Los historiadores están en contínuo proceso de repensar la forma que la historia es escrita y enseñada, pero ella todavia continua centrada en la Europa, en hombres blancos y ocidentales. Entonces, por más que se tenga avanzado en las críticas a esta perspectiva, creemos que los estudios decolonias, pueden aportar mucho para el campo de las ciencias humanas. Por lo tanto elegimos para la análisis los textos redactados por los siguientes autores: Edward W. Said, Gayatri C. Spivak, Walter D.

\footnotetext{
${ }^{1}$ Doutoranda do Programa de Pós-Graduação em História da Universidade Estadual do Oeste do ParanáUNIOESTE, Linha de pesquisa Cultura e Identidades, bolsista CAPES; Marechal Cândido Rondon, Paraná, Brasil; e-mail: danielebrocardo@gmail.com.

${ }^{2}$ Doutoranda do Programa de Pós-Graduação em História da Universidade Estadual do Oeste do ParanáUNIOESTE, Linha de pesquisa Cultura e Identidades. Professora colaboradora do Departamento de História da Universidade Estadual do Centro-Oeste-UNICENTRO; Guarapuava, Paraná, Brasil; e-mail: caroltecchio@yahoo.com.br. Trabalho apresentado no I Seminário Latino-Americano de Estudos em Cultura SEMLACult, Foz do Iguaçu/PR, Brasil, 2017.
} 
Mignolo y Boaventura de Sousa Santos. Se espera con esta análisis percibir algunas de las contribuciones que estos autores pueden traer para el conocimiento historico.

Palabras claves: Aporte teórico; Ciencias Humanas; Descolonización epistémica.

\section{Abstract}

This work was conceived during the class subject in the History Phd course of Universidade Estadual do Oeste do Paraná. In class subject we discussed theoretical texts written by authors linked to theoretical movements known as post-colonialism, subaltern studies and decoloniality. From these readings and from one activity of this subject (reading a thesis developed in History field), we have realized the absence of works in this knowledge field. Thereby, it was born the questioning which structures this work: How could these studies contribute to the writing of the History? The historians are in constant rethink process the way History is written and taught, although it yet remains centered in Europe, in White and Western men. Thus, despite criticism has been advanced in this perspective, we believe that decolonial studies can contribute much to the field of human sciences. For that, we chose for our analysis the texts developed by the following authors: Edward W. Said, Gayatri C. Spivak, Walter D. Mignolo and Boaventura de Sousa Santos. We hope this analysis lead to perceive some of the contributions these authors can bring to historical knowledge.

Keywords: Theoretical contribution, Human Sciences, Epistemic decolonization.

\section{Introdução}

A ideia de desenvolver este texto surgiu a partir da participação na disciplina Estudos Avançados em Cultura e Identidades, ministrada pela professora doutora Yonissa Marmitt Wadi, no Programa de Pós-Graduação em História da Universidade Estadual do Oeste do Paraná - UNIOESTE. Durantes os estudos discutimos os textos teóricos desenvolvidos por autoras e autores que são identificados com os movimentos teóricos conhecidos como póscolonialismo, estudos subalternos e decolonialidade. A partir destas leituras e de um trabalho propostos na disciplina, (ler uma tese desenvolvida no campo da História que utilizasse o referencial bibliográfico contemplado até então), percebemos a carência de teses e dissertações em História que dialoguem com estes movimentos teóricos.

Assim, nasceram os questionamentos que estruturam as ideais desenvolvidas neste trabalho, a saber: Por que o campo da História possui poucos trabalhos que dialogam com estes pensadores (a)? Como estes estudos podem contribuir para problematizar o uso de teorias na escrita da História?

Sabemos que os historiadores (a) estão revendo a forma de pesquisar desde o início da escola dos Annales, porém a História que continua sendo escrita e ensinada ainda está centrada na Europa, no ocidente e em homens brancos. Acreditamos que os estudos decolonias, subalternos e pós-colonialismo tem potencial para promover novas abordagens que contemplem outros sujeitos.

Deste modo, estruturamos este trabalho apresentando de forma geral as correntes teóricas em questão, e em seguida expondo algumas ideias desenvolvidas por autoras e 
autores reconhecidos por suas contribuições na perspectiva teóricas destes grupos de estudos. Os trabalhos que dialogam com estas perceptivas são mais comuns nas áreas de Direito, Sociologia e Literatura ${ }^{3}$. No Brasil encontramos algumas palestras, disciplinas e artigos, a exemplo, o artigo de Muryatan Santana Barbosa (2010, p. 77), da área história que propõem dialogar com tais estudos. No seu trabalho A crítica pós-colonial no pensamento indiano contemporâneo, nos traz um panorama das autoras e autores dentro da crítica pós-colonial e suas contribuições para as áreas de Sociologia do Conhecimento e Teoria da História.

Barbosa descreve duas visões sobre pós-colonialismo: uma entenderia este como "uma vertente de crítica textual desconstrucionista (ou pós-estruturalista), voltada para o estudo das obras colonialistas". Outra visão, entretanto, defende tal referencial "como empreendimento de crítica mais ampla e radical, voltado para a práxis" (BARBOSA, 2010, p. 69).

De tal modo, apresenta os autores Edward Said, Homi K. Bhabha e Gayatri Chakravorty Spivak como "um grupo homogêneo da crítica pós-colonial", que tiveram reconhecimento a partir dos anos 1980-90. Eles teriam em comum, além de serem intelectuais considerados do Terceiro Mundo e atuarem nas universidades da Europa e dos Estados Unidos, o fato de considerar o colonialismo e sua diferença com poder imperial como elemento criador da subjetividade e ter uma posição crítica à visão eurocêntrica presente nas ciências sociais e humanas. O autor destaca ainda o caráter político de tal ação (Barbosa, 2010, p.57-60).

O grupo Estudos Subalternos do Sul da Ásia foi descrito por Barbosa (2010, p. 63), como construtor de uma nova historiografia, centrada na realidade da Índia e que rompendo com "os paradigmas eurocêntricos da historiografia tradicional indiana de cunho modernista: nacionalista ou colonialista".

$\mathrm{Na}$ América Latina, identificado com a decolonialidade, é fundado o grupo Modernidade/Colonialidade (M/C) a partir do final dos anos 1990. Luciana Ballestrin (2013, p.89-90) no artigo América Latina e o giro decolonial nos apresenta este grupo como uma opção epistêmica, teórica e política, que é critica a permanência da "colonialidade global nos diferentes níveis da vida pessoal e coletiva", se opondo a "colonialidade do poder, do saber e do ser".

O grupo surgiu com inspiração principal no grupo Sul-Asiático dos Estudos Subalternos. Entretanto, alguns autores tiveram uma postura crítica a esta "inspiração". Para eles este estudo continuou seguindo os teóricos europeus. Era necessário descolonizar

\footnotetext{
${ }^{3}$ Ballestrin (2013, p.98) apresenta um quadro do "perfil dos membros do Grupo Colonialidade/Modernidade", suas áreas de atuação profissional, suas nacionalidades e as instituições que estão vinculados. Nenhum é da área de História, nem há brasileiros ou instituições brasileiras.
} 
epistemologicamente e também era fundamental para América Latina centrar em sua trajetória própria, que é diferente da Índia (BALLESTRIN, 2013, p.95).

Assim, o grupo latino americano de estudos subalternos foi desarticulado, nascendo em seu lugar o Grupo Modernidade/Colonialidade. Tal grupo tem como constatação que o fim do colonialismo físico na América, não findou a dominação colonial, ela continua acontecer na economia, na política e na cultura do continente. O grupo questiona que para modernidade existir, ela precisa de seu outro lado que é a colonialidade. Modernidade, aliada ao capitalismo, ao patriarcalismo e ao colonialismo, produzem qual sujeito é civilizado e deve exercer o poder. (BALLESTRIN, 2013, p. 96, p.100, p.101).

Um dos conceitos desenvolvido pelo grupo é da "colonialidade do saber", que é pensada a partir da dominação epistêmica eurocêntrica, aliada a ela está o "universalismo, sexismo e racismo". Há também, uma crítica ao sujeito epistêmico das ciências humanas, o qual com sua linguagem neutra aparenta não ter nenhuma relação de poder, como se habitasse um universo paralelo distante do restante da humanidade. (BALLESTRIN, 2013, p.103-104).

Nossa análise se concentrara agora em textos desenvolvidos por autoras e autores considerados pertencentes a estes grupos de estudos. Foram selecionados os textos de Edward W. Said e Gayatri C. Spivak, como representantes do pós-colonialismo e os textos de Walter D. Mignolo e Boaventura de Sousa Santos como representantes dos estudos decoloniais. Espera-se com esta análise expor algumas das questões levantadas por estes autores e que nos possibilitam reavaliar o conhecimento da História.

\section{Contribuições das perspectivas pós-colonialismo e decoloniais para o campo de conhecimento da História}

Para pensar as contribuições destes estudos para História antes precisamos conhecer elementos centrais de alguns trabalhos produzidos nessa área. Assim, selecionamos trabalhos de Edward W. Said, Gayatri Spivak, Walter D. Mignolo e Boaventura de Sousa Santos. Esse recorte contempla somente alguns dos nomes importantes, porém atende ao propósito de refletir de que modo a História poderia se apropriar de considerações tecidas por esse grupo.

Iniciemos por Edward W. Said ${ }^{4}$ escreveu vários livros com fundamentação póscolonial, sendo talvez o mais conhecido seja: Orientalismo: o oriente como invenção do

\footnotetext{
4 "Um dos mais importantes intelectuais palestinos, crítico literário e ativista da causa palestina." Nasceu em Jerusalém em 01 de novembro de 1935 - faleceu em Nova Iorque em 25 de setembro de 2003. Filho de árabes cristãos foi educado no Cairo/Egito. Em 1951 foi para os Estados Unidos para estudar. Estudou na Universidade de Princeton (1957) e depois Harvard (1960-1964), onde concluiu o seu doutorado. Em 1963 ingressou como docente na Universidade de Columbia, onde ensinou durante as quatro décadas, inglês e literatura comparada.
} 
ocidente, considerado como um dos textos fundadores dos estudos pós-coloniais. Todavia, nossa atenção centra-se sobre outro livro: Cultura e Imperialismo, pois neste Said (1995, p.11-12) procura pensar a cultura imperial de uma forma geral, não mais baseada na relação entre Ocidente e Oriente, e sim em uma relação ampla entre Ocidente e os "seus territórios ultramarinos" e também nas resistências, sejam elas armadas ou culturais, contra esta cultura imperial e a chegada do homem branco europeu.

Said (1995, p.12-14) tem como recorte os "impérios ocidentais modernos dos séculos XIX e XX”, basicamente o inglês, francês e norte americano. Para chegar aos objetivos do livro se utiliza de romances, compreendendo-os de duas formas: primeiro como "obras de arte e de conhecimento [...]", e em segundo lugar ligadas a construção do "processo imperial de que fazem parte de maneira explícita e inequívoca", sugerido que estudemos este lado das obras até então ignorado.

Neste livro, um dos objetivos de Said (1995, p.24) é “[...] aprofundar as linhas de pesquisa e argumentação sobre a experiência histórica do imperialismo [...]”. Sua crítica reside em pensar que estudamos quase que exclusivamente a história da Europa e do Ocidente e limitamos nosso conhecimento ainda mais por permitir que prevaleça a visão deste continente sobre os outros espaços. Said (1995, p.11) descreve aspectos marcantes nos discursos europeus sobre os outros espaços. Entre outros elementos estão "as ideias de levar a civilização a povos bárbaros ou primitivos, [...] de que se fazia necessário o açoitamento, a morte [...] porque em geral o que 'eles' melhor entendiam era a força ou a violência; 'eles' não eram como 'nós', e por isso deviam ser dominados".

Said (1995, p. 20-21.) ressalta que os romances expressam uma visão que a única ação e vida válida no mundo estão no Ocidente, "cujos representantes parecem estar à vontade para impor suas fantasias e filantropias num Terceiro Mundo retardado mental". Nesta mesma visão o Ocidente regula o que deve ser mencionado sobre o restante da humanidade, que é apresentada sem "vida, história ou cultura" independente dele, a não ser, coisas desagradáveis. Essa visão foi construída pelos romances no auge da euforia com o imperialismo, mas outras visões como esta continuam a serem afirmadas mesmo após a descolonização, a exemplo, os filmes produzidos pelos cineastas contemporâneos.

Em consonância com o questionamento levantado neste texto, Agra do Ó (2005, p.126127) situa uma série de contribuições do trabalho de Said para o ofício do historiador, entre

Foi também professor nas universidades de Harvard, Johns e Yale. Mais informações: https://pt.wikipedia.org/wiki/Edward_Said e BELIZÁRIO, F. Edward Said: mundanidade e deslocamento. Disponível: http://alice.ces.uc.pt/en/wp-content/uploads/2014/03/texto-ed-said-v4.pdf. Acesso: 13/03/2017. 
elas estão: entrelaçar as relações políticas e culturais; repensar o imperialismo; problematizar as "hierarquias entre as fontes"; “[...] pensar a própria narrativa como elemento significativo; [...] fazer do presente a ontologia do pensável; desnaturalizar o geográfico [...]" entre outras. Encera seu artigo afirmando: "É difícil pensar em um interlocutor tão oportuno para a história e para os historiadores, nos dias que vivemos, em que o império parece não ter fim, e em que a violência e a intolerância parecem ter se naturalizado".

Consideramos que essa desconstrução de modos consolidados de fazer a história pode ser correlacionada com a pergunta que dá o título ao livro de Gayatri Spivak ${ }^{5}$ (2010): Pode o Subalterno Falar?. Repensar hierarquias entre fontes e sujeitos da história implica em negar a colonialidade do poder e buscar novos olhares para a história.

O livro de Gayatri Spivak é um marco na área de crítica cultural e se insere no contexto de estudos pós-coloniais e desconstrutivistas. É importante lembrar que a autora estuda tradução, e sua análise versa sempre sobre essa temática, sendo necessárias ressalvas para aplicar os conceitos por ela trabalhados em outros contextos. Portanto, perguntar sobre as contribuições de Spivak para a história implica em considerar sua leitura crítica da produção acadêmica, não simplesmente a aplicação de conceitos cunhados por essa autora.

Spivak critica o agenciamento, num processo que leva à ilusão de cumplicidade do intelectual. De certa forma, o Terceiro Mundo é intraduzível para o Primeiro Mundo, e não cabe ao intelectual falar pelo subalterno. Sugere e convoca então os intelectuais, especialmente as mulheres, para criarem espaços em que os subalternos se articulem e sejam ouvidos, sem agenciamento. Inserida em estudos feministas, afirma que se a condição do subalterno é complicada, da mulher subalterna é pior ainda. "Se, no contexto da produção colonial, o sujeito subalterno não tem história e não pode falar, o sujeito subalterno feminino está ainda mais profundamente na obscuridade" (SPIVAK, 2010, p.67).

O subalterno em Spivak pode ser relacionado ao sujeito invisível sobre o qual nos fala Boaventura de Sousa Santos ${ }^{6}$. Esse silêncio pela ausência de vocalidade é sentido em Santos,

\footnotetext{
${ }^{5}$ Gayatri Spivak nasceu em Calcutá, na Índia, em 1942. Estudou literatura comparada em seu mestrado e doutorado na Universidade Cornell nos Estados Unidos, onde foi orientada pelo crítico literário Paul de Man, que posteriormente integrou a linha teórica desconstrucionista da Universidade Yale. Atualmente é professora de Literatura Comparada do Departamento de Letras e do Instituto de Literatura e Sociedade Comparadas, da Universidade Columbia, em Nova Iorque.

6 Boaventura de Sousa Santos é professor da Faculdade de Economia da Universidade de Coimbra e Distinguished Legal Scholar da Universidade de Wisconsin-Madison. Nasceu em Coimbra em 15 de Novembro de 1940, realizou seu doutorado em Sociologia do Direito pela Universidade de Yale no ano 1973. Atualmente é diretor do Centro de Estudos Sociais da Universidade de Coimbra e coordenador Científico do Observatório Permanente da Justiça Portuguesa. No período de 1 de julho de 2011 até 31 de dezembro de 2016 atuou como
} 
que em outras palavras traduz isso pela não visibilidade. Podemos ler isso no capítulo Para além do Pensamento Abissal: das linhas globais a uma ecologia de saberes, escrito pelo autor.

Santos (2009, p.23-24) afirmar em seu texto que o "pensamento moderno ocidental é um pensamento abissal”, que se divide entre os visíveis e os invisíveis, através de uma linha, deste e daquele lado. Assim, um lado desaparece como realidade, tronando-se inexistente de maneira radical. Esta distinção é a que ocorre entre as sociedades metropolitanas e os territórios coloniais.

A dicotomia aplicada às sociedades metropolitanas é da regulação/emancipação, já das sociedades coloniais é da apropriação/violência. Ambas as dicotomias são inconcebíveis para serem aplicadas do outro lado da linha. As manifestações que melhor representam o pensamento abissal são: o conhecimento (podemos inserir aqui a História) e o direito moderno. São as duas linhas abissais principais, atuam de maneira diferente, mas dependentes (SANTOS, 2009, p.25).

Assim, no campo do conhecimento, a ciência moderna possui o monopólio da distinção entre o verdadeiro e o falso, entre o científico e o não científico, em detrimento dos demais conhecimentos. Estão do lado não científico, os conhecimentos dos populares, dos indígenas. Deste lado, "não há conhecimento real; existem crenças, opiniões, magia,...” (SANTOS, 2009, p.25). Já, no campo do direito moderno, o que divide os lados da linha: é o legal ou ilegal, se constituindo nas únicas duas formas de existência perante a lei.

Contra o sistema abissal faz-se necessária uma resistência, tanto política como epistemológica, um pensamento pós-abissal. O pensamento pós-abissal defende o princípio da igualdade, reconhece a diferença e preconiza a ideia que a diversidade epistemológica do mundo é inesgotável. Exige uma radical ruptura com as modernas formas de pensamento e ação ocidentais. É necessário buscar do outro lado da linha formas de combater o pensamento abissal, ou seja, é preciso olhar para o Sul global, fruto das injustiças do capitalismo e do colonialismo (SANTOS, 2009, p.44).

Levar em conta a estrutura do conhecimento que separa e hierarquiza os saberes é tarefa assumida também por Walter Mignolo $^{7}$ (2003), em seu livro Histórias Locais/Projetos

dirigente do projeto de investigação ALICE - Espelhos estranhos, lições imprevistas. Disponível: http://www.ces.uc.pt/projectos/?prj=4408\&id_lingua=1. Acesso: 30/01/2017.

\footnotetext{
${ }^{7}$ Walter Mignolo é argentino, professor de Literatura e Antropologia e diretor do Centro de Estudos Globais e Humanidades da Universidade de Duke nos Estados Unidos.
} 
Globais: colonialidade, saberes subalternos e pensamento liminar, nos instiga a pensar na relevância dos estudos pós-coloniais para a história.

O autor inicia argumentando que no século XVI os missionários espanhóis classificavam os povos por dominarem ou não a escrita. Nos séculos XVIII e XIX o critério passa a ser a história, não a escrita. Permanece a diferença colonial imposta e naturalizada no processo de colonização. Para questionar essa ordem Mignolo propõe o pensamento liminar, ou seja, um pensamento crítico com vistas à descolonização do pensamento. A diferença colonial deve, nessa perspectiva, ser superada por meio da elaboração de um "outro pensamento".

Mignolo defende que a razão subalterna lute por seus saberes, especialmente aqueles subjugados no processo de colonização. A colonialidade do poder seria a base que articula a produção do conhecimento, fazendo com que os saberes e as histórias locais europeias fossem vistos como projetos globais. Nesse projeto global, a América está inserida como a continuação da Europa, logo, os saberes aqui produzidos estão à margem.

Existem trabalhos sobre a modernidade e outros sobre colonialidade, mas não há diálogo, afinal, a modernidade acontece na Europa, e a colonialidade fora dela. Assim, as histórias locais absorvem projetos globais, sendo perfeitamente aceito falar de Portugal sem mencionar o Brasil, mas não se pensa o Brasil desvinculado da colonização portuguesa. $\mathrm{O}$ conhecimento posto dessa forma está naturalizado, é aceito pela sociedade e pela academia.

Uma das principais críticas pós-coloniais e levantadas por Mignolo é o uso de teorias criadas em outros contextos geoistóricos. Há um limite para ser observado em relação à colonialidade do poder, sendo imprescindível dar lugar à uma produção do conhecimento independente dos processos coloniais.

\section{Considerações finais}

Os textos aqui debatidos foram apresentados de forma breve. Mas, a partir da leitura do texto de Barbosa (2010, p. 67-68), podemos afirmar que o grupo Estudos Subalternos do Sul da Ásia contribui para repesar a historiografia rompendo com as categorias da modernidade que organizam a compressão do passado de forma homogenia e linear. $\mathrm{O}$ grupo sai em defesa da ampla interdisciplinaridade, o que contribuiria para melhor interpretação das fontes. No que podemos chamar de diálogo teórico critico, talvez impensável para alguns historiadores, entre "o marxismo e o pensamento acadêmico francês- estruturalista e pós-estruturalista -" também na crítica feita a ideia da Europa como único centro produtor de ciência e no caráter incompleto da cientificidade das ciências humanas (BARBOSA, 2010, p. 70). 
Ballestrin (2013, p.111) escreve o que acredita ser mais "original dos estudos decoloniais" que é "as novas lentes colocadas sobre velhos problemas latino-americanos". Também, tece algumas criticas a estes estudos, por exemplo, sobre faltar de discussões sobre o Brasil, além de não existir nem "pesquisador (a) brasileiro (a) associado ao grupo".

Novos olhares para a História podem ser construídos a partir dos estudos póscolonialismo, subalternos e decolonialidade. A descolonização dos saberes exige abandonar modelos consolidados de pesquisa, buscando uma leitura autêntica de objetos de estudo. Não basta reproduzir os modelos nos quais a história dos colonizados já foi contada, é preciso refletir sobre como o conhecimento é construído e quais amarras ainda mantemos em nosso pensamento colonizado. Além disso, é preciso prestar atenção às resistências a este pensamento e ação colonial.

\section{Referências}

AGRA DO Ó, Alarcon. Edward Said: entre a crítica literária e a operação historiográfica. Saeculum - Revista de História, n.12, João Pessoa, jan./jun. 2005.

BALLESTRIN, Luciana. América latina e o giro decolonial. Revista Brasileira de Ciência Política, n. 11, Brasília, maio-agosto 2013, p. 89-117.

BARBOSA, Muryatan Santana. A crítica pós-colonial no pensamento indiano contemporâneo. Afro-Ásia, n. 39, Salvador, 2010, p. 57-77.

MIGNOLO, Walter D. História locais / Projetos globais: colonialidade, saberes subalternos e pensamento liminar. Belo Horizontes: Ed. da UFMG, 2003.

SAID, Edward W. Cultura e imperialismo. São Paulo: Companhia das Letras, 1995.

SANTOS, Boaventura de Souza; MENESES, Maria Paula (Orgs.). Epistemologias do Sul. Coimbra, PT: Ed. Almendina; CES, 2009.

SPIVAK, Gayatri Chakravorty. Pode o subalterno falar? Belo Horizonte: Editora UFMG, 2010. 